\title{
Correlation of Sonographic Grading of Renal Cortical Echogenicity with Serum Creatinine in Patients with Chronic Kidney Disease
}

\author{
Chidananda Murthy. $\mathbf{M}^{1}$, Bharath Kumar Shettty $\mathrm{K}^{1}$, Ganesh $\mathrm{K}^{2}$, Francis N. P. Monteiro ${ }^{3}$ \\ ${ }^{1}$ Assistant Professor, Department of Radio-Diagnosis, A.J. Institute of Medical Sciences and Research Centre, ${ }^{2}$ Professor \& HOD, Department of Radio-Diagnosis, \\ A.J. Institute of Medical Sciences and Research Centre, ${ }^{3}$ Professor, Department of Forensic Medicine \& Toxicology, A.J. Institute of Medical Sciences and \\ Research Centre, NH 17, Kuntikana, Mangalore -575004.
}

\section{Abstract}

Background: Ultrasound Imaging can be used as a painless, non-invasive modality for the grading of renal echogenicity in chronic kidney disease (CKD). Aims: To determine the association of renal echogenicity in persons with CKD using ultrasound and serum creatinine Settings and Design: Retrospective observational study design at a single center. Subjects and Methods: The study included 112 subjects aged 18 to 90 years with CKD, with grades of renal echogenicity and renal length estimates based on ultrasound findings and biochemical test results of serum creatinine profile. Renal size was categorized as optimal or small or enlarged and renal echogenicity graded from 1 to 4 . Statistical Analysis used: A one way Analysis of Variation test (ANOVA) was used to compare the renal echogenicity and renal length with serum creatinine. Pairwise correlations were estimated and a p value of $<0.05$ was considered as statistically significant. Results: The study included 112 subjects with a mean age (SD) of 54.37 (17.29 years) and $81(72.32 \%)$ subjects were males. The majority of patients ( $\mathrm{n}=51$, $45.54 \%)$ in the study were aged 60 years or older. Sixty eight subjects $(60.71 \%, 95 \%$ CI: $51.45,69.43)$ subjects had optimal sized kidneys and 8 (7.14\%, 95\% CI: $3.66,13.46)$ subjects had significant discrepancy in renal size. The majority of subjects (n=43, 38.74\%, 95\%CI: 29.73 , 47.64) in the study had Grade 1 renal echogenicity. Serum creatinine values increased significantly with increasing grades of renal echogenicity $(\mathrm{F}=9.58, \mathrm{p}<0.001$, one way ANOVA test). The grade of echogenicity and serum creatinine levels showed a statistically significant correlation $(\mathrm{p}<0.001)$ on pairwise correlation test. The mean longitudinal renal length was significantly associated $(\mathrm{F}=14.07$, $\mathrm{p}<0.001)$ with renal echogenicity. Conclusion: Serum Creatinine levels and renal echogenicity were significantly associated in this study. Ultrasound imaging studies can be a painless non-invasive alternate in the evaluation of CKD.

Keywords: Ultrasound, chronic kidney disease, renal length, renal echogenicity, serum creatinine.

Corresponding Author: Dr. Francis N. P. Monteiro, Professor, Department of Forensic Medicine \& Toxicology, A.J. Institute of Medical Sciences and Research Centre, NH 17, Kuntikana, Mangalore -575004.

Received: October 2018

Accepted: November 2018

\section{Introduction}

Chronic Kidney Disease (CKD), a common cause of renal failure is characterized by progressive loss of the structural and functional integrity of the kidney, with or without decreased glomerular filtration rate (GFR). ${ }^{[1]}$ CKD may be diagnosed by pathological, biochemical or imaging investigations. ${ }^{[1]}$ Ultrasound provides a non-invasive, painless, easily accessible modality to visualize the kidneys and assess renal sufficiency and progression of renal disease. ${ }^{[2-4]}$ A small kidney with a thin echogenic cortex or parenchyma on imaging studies may indicate irreversible damage. ${ }^{[2-4]}$ Serum Creatinine, a biochemical test, can also be used to estimate GFR and the stage of CKD but is an invasive test. ${ }^{[5]}$ An estimated 800 per million population in India may have CKD and the incidence of end stage renal disease is approximately $150-200$ per million population. ${ }^{[6]}$ This study aimed to correlate renal parenchymal echogenicity and renal size with serum creatinine among patients graded for CKD using ultrasound at a teaching hospital in south India.

\section{Subjects and Methods}

An observational study design was used to identify medical records of patients diagnosed with CKD at the study institute between January 2018 and July 2018. The study protocol was approved by the institutional ethics committee and informed consent was waived as this as a retrospective study with data retrieval from medical records. Consecutive patients aged 18 years or above, diagnosed with CKD based on the guidelines of the National Kidney Foundation1, were included in the study and patients with kidney replacement therapy, fatty liver and other liver diseases were excluded from the study.

Renal ultrasound exams were performed using PHILIPS EPIC 5G machine and C 5-1 Pure Wave probes. The length of the kidneys were measured pole to pole. Renal Parenchyma thickness was measured from the renal hilum to the maximum convex border of the lateral renal margin. Cortical thickness was measured in the sagittal plane perpendicular to the capsule and over the medullary pyramid. The mean values of the right and left renal 


\section{Murthy et al; Chronic Fidney Disease}

longitudinal size was estimated. Renal cortical echogenicity was compared and graded with the echogenicity of the liver and renal medulla and categorized based on the guidelines developed by Sidappa et al. ${ }^{[7]}$ Grade 0 [Figure 1] was considered a normal echogenicity less than that of the liver with maintained corticomedullary definition. Grade 1 [Figure 2] was considered as echogenicity same as that of the liver and maintained corticomedullary definition. Grade 2 [Figure 3] as echogenicity greater than that of the liver with maintained corticomedullary definitions, Grade 3 [Figure 4] as echogenicity greater than that of the liver and poorly maintained corticomedullary definitions and Grade 4 [Figure 5] as echogenicity greater than that of the liver and loss of corticomedullary definitions.

A renal length $<8 \mathrm{~cm}$ was considered as a small kidney and renal lengths greater than $12 \mathrm{~cm}$ as enlarged.3,4,8, A difference of $\geq 2 \mathrm{~cm}$ between kidneys was considered as indicative of significant size discrepancy between the two kidneys.3,4 Details of the serum creatinine estimations done for the patients with CKD were retrieved from the medical records.

Data was initially entered into a MS Excel spreadsheet and exported into a statistical software (STATA Version 10.0, College Station, TX, USA) for statistical analysis. The association of serum creatinine with renal echogenicity was analysed using a one way Analysis of Variance (ANOVA) test and pair wise correlation tests estimating a Pearson correlation coefficient. 95\% confidence intervals (CI) were estimated for point estimates and a $p$ value $<0.05$ was considered as statistically significant.

\section{Results}

The study included 112 subjects with a mean age (SD) of 54.37 (17.29 years) and $81(72.32 \%)$ subjects were males. The majority of patients in the study were aged 60 years and above [Table 1]. Sixty eight subjects $(60.71 \%, 95 \% \mathrm{CI}$ : $51.45,69.43)$ subjects had optimal sized kidneys and only 8 $(7.14 \%$, 95\% CI: $3.66,13.46)$ subjects had significant discrepancy in renal size [Table 2]. The majority of subjects $(\mathrm{n}=43,38.74 \%, 95 \% \mathrm{CI}: 29.73,47.64)$ in the study had Grade 1 renal echogenicity [Table 2]. The mean serum creatinine values in the study were $5.56 \pm 3.78 \mathrm{mg} / \mathrm{dl}$ (median $5.55 \mathrm{mg} / \mathrm{dl}$ ). Serum creatinine values increased significantly [Table 3] with increasing grades of renal echogenicity ( $F=9.58, p<0.001$, one way ANOVA test). The grade of echogenicity and serum creatinine levels showed a statistically significant correlation $(\mathrm{p}<0.001)$ on pairwise correlation test. Renal size did not show a significant correlation with serum creatinine $(\mathrm{R}=0.03, \mathrm{p}=0.21)$ in this study. The mean longitudinal renal length was significantly associated $(\mathrm{F}=14.07, \mathrm{p}<0.001)$ with renal echogenicity in this study [Table 4].

Table 1: Distribution of patients with CKD in the study by age.

\begin{tabular}{|c|c|}
\hline Table 1: Distribution of patients with CKD in the study by age. \\
\hline Age & $\mathbf{N}(\%)$ \\
\hline$<30$ years & $14(12.50)$ \\
\hline $31-40$ years & $10(8.93)$ \\
\hline $41-50$ years & $14(12.50)$ \\
\hline $51-60$ years & $23(20.54)$ \\
\hline$>=60$ years & $51(45.54)$ \\
\hline
\end{tabular}

Table 2: Ultrasound determined discrepancy in renal size and renal lengths among study patients.

\begin{tabular}{|c|c|}
\hline Renal Parameters & $\mathbf{N}(\mathbf{\%})$ \\
\hline Renal size difference $>2 \mathrm{~cm}$ & $8(7.14)$ \\
\hline Small size Kidneys (any kidney $<8 \mathrm{~cm})$ & $35(31.25)$ \\
\hline Large size Kidneys (any kidney $>12 \mathrm{~cm})$ & $9(8.04)$ \\
\hline Grade 1 echogenicity & $43(38.74)$ \\
\hline Grade 2 echogenicity & $36(32.43)$ \\
\hline Grade 3 echogenicity & $29(26.13)$ \\
\hline Grade 4 echogenicity & $3(2.70)$ \\
\hline
\end{tabular}

Table 3: Serum Creatinine and Grades of Renal Echogenicity in the study subjects.

\begin{tabular}{|c|c|c|}
\hline $\begin{array}{c}\text { Grade of Renal } \\
\text { echogenicity }\end{array}$ & $\begin{array}{c}\text { Serum Creatinine } \\
\text { Mean } \pm \text { SD }\end{array}$ & \multirow{2}{*}{ F, P value } \\
\hline Grade 1 & $3.86 \pm 2.78$ & \multirow{2}{*}{$\mathrm{F}=9.58, \mathrm{p}<0.001$} \\
\hline Grade 2 & $5.87 \pm 3.12$ & \\
\hline Grade 3 & $6.95 \pm 4.22$ & \\
\hline Grade 4 & $12.61 \pm 6.04$ & \\
\hline Total & $5.56 \pm 3.78$ & \\
\hline
\end{tabular}

Table 4: Mean Longitudinal Renal Length and Grades of Renal Echogenicity in the study subjects

\begin{tabular}{|c|c|c|}
\hline $\begin{array}{c}\text { Grade of Renal } \\
\text { echogenicity }\end{array}$ & $\begin{array}{c}\text { Mean Longitudinal } \\
\text { Renal Length } \\
\text { Mean } \pm \text { SD }\end{array}$ & \multirow{2}{*}{ F, P value } \\
\hline Grade 1 & $10.03 \pm 1.42$ & \\
\hline Grade 2 & $8.65 \pm 1.51$ & \\
\hline Grade 3 & $8.61 \pm 1.11$ & \\
\hline Grade 4 & $6.08 \pm 0.42$ & \\
\hline Total & $9.11 \pm 0.001$ \\
\hline
\end{tabular}

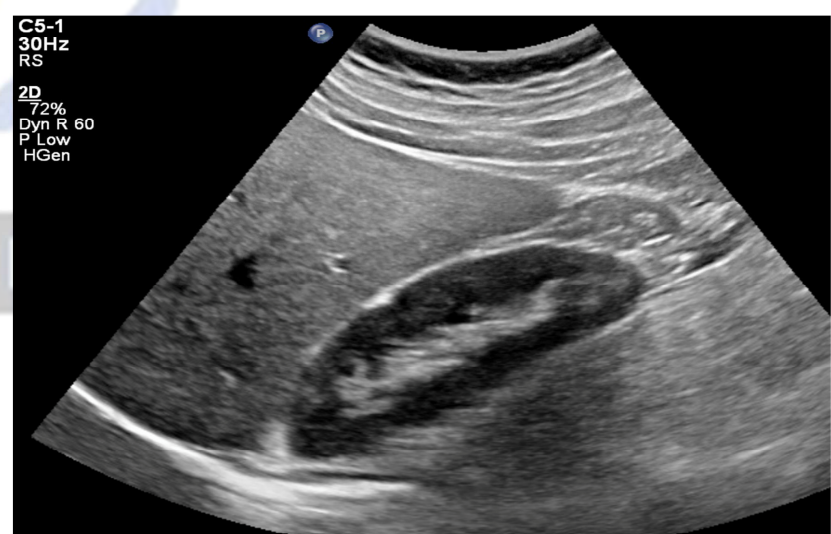

Figure 1: Grade 0 (Normal echogenicity less than that of the liver with maintained CMD)






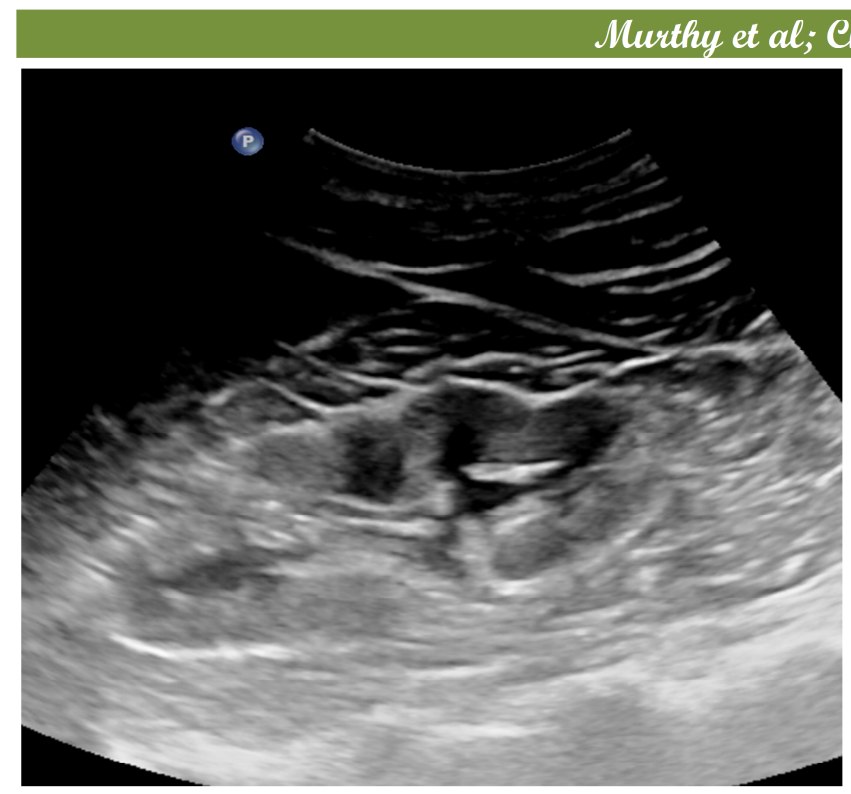

Figure 3: Grade II (Echogenicity greater than that of the liver with maintained CMD)

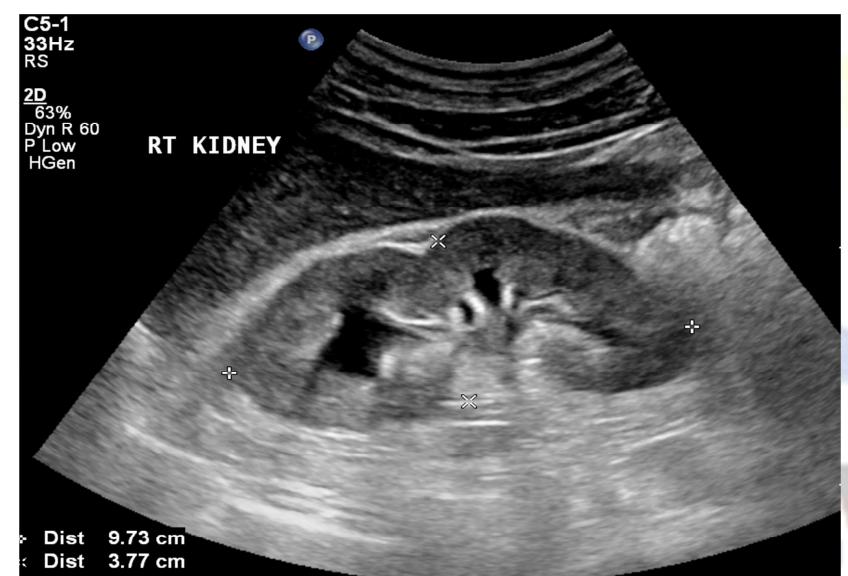

Figure 4: Grade III (Echogenicity greater than that of the liver with poorly maintained $\mathrm{CMD}$ )

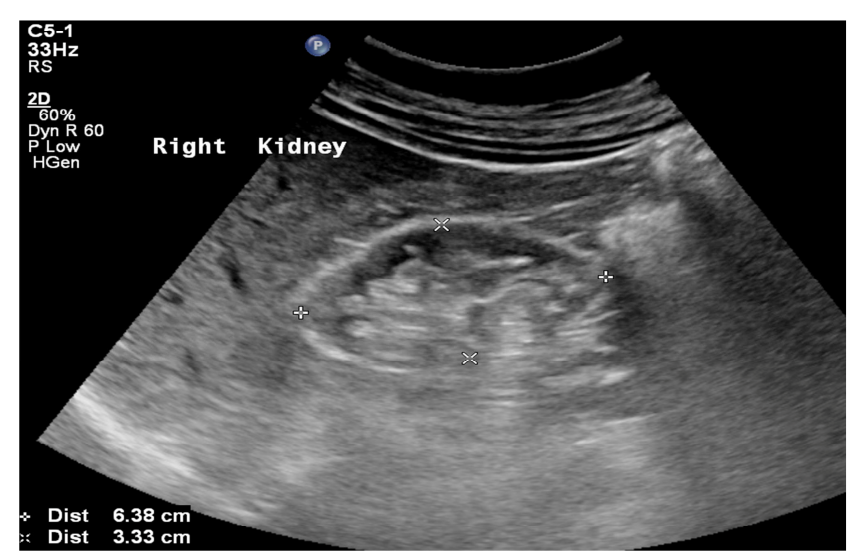

Figure 5: Grade IV (Echogenicity greater than that of the liver with loss of CMD)

Discussion

Previous studies have shown that renal echogenicity has a strong correlation with histopathologic findings. ${ }^{[9-11]}$ A highly echogenic cortex was a common finding and cortical echogenicity was associated with global sclerosis, focal tubular atrophy, focal leukocytic infiltration..$^{[9-11]}$ Our results are similar to these studies. Grade 1 echogenicity was slightly more prevalent in this study and is consistent with the findings reported in a previous study from India. ${ }^{[8]}$

Nearly $40 \%(n=44,39.39 \%)$ of subjects in the study had an abnormal renal size and $7.14 \%$ subjects had a significant discrepancy in the size of the two kidneys. These findings are consistent with previous studies. ${ }^{[6,12]}$ Renal length is often considered a surrogate marker of renal function. The mean renal length in our study $(9.11 \pm 1.59 \mathrm{cms})$ was similar to that reported in previous studies. ${ }^{[6,13]}$

Serum creatinine levels was significantly associated with renal echogenicity in this study and is consistent with reports from previous studies. ${ }^{[6,8]}$ Serum creatinine levels were not significantly associated with renal length in this study and is consistent with previous studies. ${ }^{[6,8]}$ The association of renal length with serum creatinine levels may be confounded by body height, weight and BMI of adults. ${ }^{[3,14,15]}$ Associated co-morbidity, especially diabetes mellitus, is another potential confounder. Renal hypertrophy in diabetic nephropathy affects all components and the kidney may maintain its structural integrity in the early phases. ${ }^{[6,16]}$ This may make the kidney appear normal or bigger in comparison to kidneys affected by other chronic renal diseases and a diabetic kidney may retain normal size even in end stage renal disease. ${ }^{[6,16]}$

The study has several limitations. The retrospective nature of data collection limited to a single center is a limitation that can affect generalization of the results and may have influenced the distribution of patients with grades of renal echogenicity. Ultrasound evaluations are operator and skill dependent and it is possible that a subjective bias may have been introduced during the examinations and reporting. However, the present study shows that ultrasound imaging studies and renal echogenicity are useful in CKD and offer an easier, non-invasive, painless alternate to the identification and grading of CKD. Renal cortical echogenicity is usually irreversible, unlike serum creatinine that can reverse with therapy, and may provide a better indicator of the state of the disease. Further prospective studies from multiple centers across India can help toestablish the utility of ultrasound imaging and renal echogenicity in the evaluation of CKD.

\section{Conclusion}

Serum Creatinine levels and renal echogenicity were significantly associated in this study. Ultrasound imaging studies can be a painless non-invasive alternate in the evaluation of CKD.

\section{References}

1. National Kidney Foundation: Bailie GR, Uhlig K, Levey AS. Clinical practice guidelines in nephrology. Fvaluation, classification, and stratification of chronic kidney disease. Am J Kidney Dis. 2002; 


\section{Murthy et al; Chranic Kidney Disease}

39(suppl 2):S1-266

2. Khati NJ, Hill MC, Kimmel PL. The role of ultrasound in renal insufficiency: the essentials. Ultrasound Q. 2005;21:227-44

3. O' Neill WC. Sonographic evaluation of renal failure. Am J Kidney Dis. 2000;35:1021-38

4. O'Neill WC. Chronic renal failure. In: O'Neill WC, editor. Atlas of renal ultrasonography. Philadelphia: W.B. Saunders Company; 2001:p41-3

5. Tietz NW. Textbook of clinical chemistry. Philadelphia. W.B. Saunders co: 1994.p1531

6. Singh A, Gupta K, Chander R, Vira M. Sonographic grading of renal cortical echogenicity and raised serum creatinine in patients with chronic kidney disease. J. Evolution Med. Dent. Sci. 2016; 5(38):22792286

7. Sidappa K, Singla S, Al Ameen M, Rakshith SC, Kumar N. Correlation of ultrasonographic parameters with serum creatinine in chronic kidney disease. J Clin Imaging Sci. 2013;3: 28

8. Fiorinin F, Barozzi L. The role of ultrasonography in the study of medical nephropathy, J Ultrasound. 2007;10(4):161-7

9. Moghazi S, Jones E, Schroepple J, Arya K, McClellan W, Hennigar RA, et al. Correlation of renal histopathology with sonographic findings. Kidney Int.2005;67:1515-20
10. Paivansalo M, Huttunen K, Suramo I. Ultrasonographic findings in renal parenchymal diseases. Scand J Urol Nephrol. 1985;19:1 19-23

11. Hricak H, Cruz C, Romanski R, Uniewski MH, Lewin NW, Madrazo BL, et al. Renal Parenchymal disease: Sonographic-histologic correlation. Radiology. 1982;144:141-7

12. Moccia WA, Kaude JV, Wright PG, Gaffney EF. Evaluation of chronic renal failure by digital grey scale ultrasound. Urol Radiol. $1980 ; 2(1): 1-7$

13. Yamashita SR, Von Atzingen AC, Iared W,Bezzera AS, Ammirati AL Canziani ME, et al. Value of renal cortical thickness as a predictor of real function impairment in chronic renal disease patients. Radiol Bras. 2015:48(1):12-6

14. Miletic D, Fuckar Z, Sustic A, Mozetic V, Stimac D, Zauhar G. Sonographic measurement of absolute and relative renal length in adults. J Clin Ultrasound 1998;26:185-9

15. El-Reshaid W, Abdul Fattah H. Sonographic assessment of renal size in healthy adults. Med Princ Pract. 2014;23(5):432-36

16. Buturovic J, Visnar-perovic A. Ultrasonography in chronic renal failure. Eur J Radiol 2003;35(6):1021-38

Copyright: (C) the author(s), publisher. Asian Journal of Medical Radiological Research is an Official Publication of "Society for Health Care \& Research Development". It is an open-access article distributed under the terms of the Creative Commons Attribution Non-Commercial License, which permits unrestricted non-commercial use, distribution, and reproduction in any medium, provided the original work is properly cited.

How to cite this article: Murthy MC, Shettty KBK, Ganesh K, Monteiro FNP. Correlation of Sonographic Grading of Renal Cortical Echogenicity with Serum Creatinine in Patients with Chronic Kidney Disease. Asian J. Med. Radiol. Res. 2018;6(2):27-30.

DOI: dx.doi.org/10.21276/ajmrr.2018.6.2.8

Source of Support: Nil, Conflict of Interest: None declared. 